and impact of the illness. Over time, this resulted in a dwindling network of social and emotional support, affecting family-life, relationships and mental health of both patient and caregiver.

Another strain was the complex mutual process of coping and the lack of frank communication about the condition between the partners, towards their social network and the medical staff. This is partly due to the indolent course of the disease, but also due to fear of what the future would hold and lack of insight in prognosis.

Caregivers reported that care provided at the hospital did not actively involve caregivers, nor provided them with the much-needed information with regard to prognosis, long-term treatment plans or daily care.

Conclusion: SSc has a major impact on the lives of caregivers, however, current care does not actively inform, include or support them to relieve some of this burden. Further research should focus on the modalities in which caregivers can be involved in the care and which information and support is required.

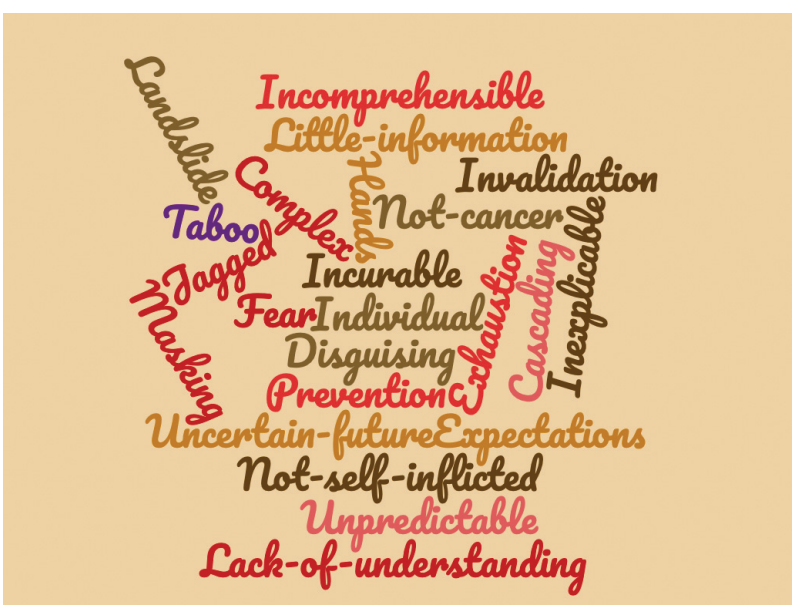

Figure 1. Word cloud/associations by participants, as part of the method used in focus group discussion.

Disclosure of Interests: Rita Schriemer: None declared, Julia Spierings Grant/research support from: Boehringer Ingelheim, Jeska de Vries-Bouwstra: None declared, Lian De Pundert: None declared, C.H.M. van den Ende: None declared, Madelon Vonk Grant/research support from: MadeIon Vonk has received unrestricted research funds from Actelion and Therabel, Consultant for: Madelon Vonk was a consultant for Actelion, Boehringer-Ingelheim, Speakers bureau: Actelion, Boehringer-Ingelheim, Roche

DOI: 10.1136/annrheumdis-2019-eular.6815

\section{PARE0020 EXERCISE FOR LUPUS PATIENTS}

Jeanette Andersen. Lupus Europe, Romford, Essex, United Kingdom

Background: Up to $80 \%$ of all Lupus patients experience fatigue and most of them report this as the most severe symptom. One of the major causes of morbidity in SLE patients is chronic, debilitating fatigue, decreasing quality of life, increasing risk of work disability with associated cumbersome healthcare costs.

Several research papers show that the only thing clinically proven to have an effect on Lupus fatigue is moderate exercise. If you tell this to a Lupus patient experiencing fatigue, however, you will find it very difficult to motivate them to exercise. The challenge is to make them realise that exercise does not necessarily mean running a marathon or going to the gym - a little movement goes a long way.

Objectives: To get lupus patients to exercise and thereby experience less fatigue/better manage their disease.

Methods: Develop an exercise program, that is approved by physiotherapists and leading lupologists, easy to do and inspires Lupus patients to keep active even when they feel exhausted.

Results: In collaboration with physical therapists Lupus Europe has developed an exercise program from our own experiences and had it approved by leading European lupologists. The program has five levels; from lying in bed up until being able to run and jump. All exercises can be done at home without training tools. In order to make it accessible we have planned to make five videos (with Lupus patients), shoving how to do each exercise and five connected pamphlets. We have already recorded the first three levels and are planning to finish the entire "package" in 2019. The materials will be made available to all Lupus patients on the Lupus Europe web site and YouTube channel free of charge.

Conclusion: We have already seen good results within the Lupus community, where people are finding the program easy to use and a help to keeping them active. Our hope is, that researchers will use our program to investigate its effectiveness on Lupus fatigue.

\section{REFERENCES}

[1] Piper BF. Pathophysiological Phenomena in Nursing: Human Responses to Illness. PA, USA: WB Saunders; 1993. pp. 279-302

[2] Ramsey-Goldman R, Rothrock N. Fatigue in systemic lupus erythematosus and rheumatoid arthritis. PM R. 2010 May; 2(5):384-92.

[3] Da Costa D, Dritsa M, Bernatsky S, Pineau C, Ménard HA, Dasgupta K Keschani A, Rippen N, Clarke AE. Dimensions of fatigue in systemic lupus erythematosus: relationship to disease status and behavioral and psychosocial factors. J Rheumatol. 2006 Jul; 33(7):1282-8.

[4] Wang C, Mayo NE, Fortin PR. The relationship between health related quality of life and disease activity and damage in systemic lupus erythematosus. J Rheumatol. 2001 Mar; 28(3):525-32.

[5] Al Dhanhani AM, Gignac MA, Su J, Fortin PR. Work disability in systemic lupus erythematosus. Arthritis Rheum. 2009 Mar 15; 61(3):378-85.

[6] Panopalis P, Yazdany J, Gillis JZ, Julian L, Trupin L, Hersh AO, Criswell LA, Katz P, Yelin E. Health care costs and costs associated with changes in work productivity among persons with systemic lupus erythematosus. Arthritis Rheum. 2008 Dec 15; 59(12):1788-95.

[7] Ramsey-Goldman R, Schilling EM, Dunlop D, Langman C, Greenland P, Thomas RJ, Chang RW. A pilot study on the effects of exercise in patients with systemic lupus erythematosus. Arthritis Care Res. 2000 Oct; 13 (5):262-9.

Acknowledgement: Mols Fysioterapi Disclosure of Interests: None declared DOI: 10.1136/annrheumdis-2019-eular.1424 